\title{
Atypical Presentation of a Case of Hemoglobin E Trait with Gaucher's Disease
}

\author{
Sucharita Datta, $\mathrm{MD}^{1,}$ Saumyen De, $\mathrm{MD}^{2}$ \\ ${ }^{1,2}$ Associate Professor, Department of Pediatrics,Nilratan Sircar Medical College, West Bengal University of \\ Health Sciences, India
}

\begin{abstract}
Hemoglobin E heterozygotes ( $H b A E$ ) are asymptomatic and homozygotes ( $H b E E$ ) have a mild microcytic anemia ${ }^{[1]}$. However, we had a 2 year old female child presenting with moderate pallor necessitating blood transfusions at 6 months to 1 year interval starting from eight months of age. Thorough clinical examination and investigative work-up revealed $\mathrm{Hb}$ E trait with Gaucher's disease. To the best of our knowledge, we are reporting for the first time the association of $\mathrm{Hb} E$ trait with enzyme-study confirmed Gaucher's disease. Earlier, there have been three case reports of Gaucher-like cells or Pseudo-Gaucher cells ( not Gaucher's disease) associated with classic beta thalassemia major, $\mathrm{Hb}$ E disease (HbEE) and thalassemia intermedia $^{[2],[3]}$. It is therefore desirable to understand whether the co-existence of a thalassemia-like syndrome and a storage disease like Gaucher's disease could influence the clinical expression of each other.

Keywords - Bone marrow biopsy, Gaucher cells, HbE trait, Liver biopsy, Leukocyte betaglucosidase,plasma chitotriosidase

Abbreviations: dl : deciliter, Fig. : Figure, Gm : Gram, Hb :Hemoglobin, HBsAg : Hepatitis B surface antigen, $H C V$ : Hepatitis $C$ virus, HPLC : High-performance liquid chromatography,mm3 : cubic millimeter, RBC : red blood cells, RDW : Red cell distribution width, PAS : Periodic acid-Schiff, Thal : Thalassemia
\end{abstract}

\section{INTRODUCTION}

$\mathrm{HbE}$ trait is an asymptomatic entity on its own, with no clinical significance, unlike compound heterozygous state (HbE- Thal). However the need for repeated blood transfusions in $\mathrm{Hb} \mathrm{E}$ trait (Hemoglobin electrophoresis and HPLC proven) especially associated with moderate splenohepatomegaly called for further work-up and confirmed Gaucher's disease, thereby explaining the unusual requirement of several blood transfusions in $\mathrm{Hb} \mathrm{E}$ trait. We strongly believe that this is the first such report of a case of $\mathrm{Hb} \mathrm{E}$ trait with Gaucher's disease.

\section{CASE REPORT}

A $2 \frac{1}{2}$ year old girl presented to us with moderate pallor and abdominal enlargement. On palpation, the liver was enlarged $5 \mathrm{~cm}$ below the costal margin with left lobe enlarged $6 \mathrm{~cm}$ at the epigastrium. It was firm in consistency with a well defined margin. The spleen was palpable about $10 \mathrm{~cm}$ along its long axis. She had her first blood transfusion at 8 months of age at a hemoglobin level of $6.7 \mathrm{gm} / \mathrm{dl}$ with some evidence of hemolysis in the form of hypochromia, microcytosis, anisopoikilocytosis and polychromasia. Her platelet count started showing a rapid decline over the next 6 months (as suggested by her sequential reports) though the haemoglobin level was maintained in the range of 7-11 gm/dl. The leukocyte count showed a gradual falling trend too. $\mathrm{Hb}$ electrophoresis of the mother ( in alkaline buffer $\mathrm{pH} 8.6$ ) showed $\mathrm{HbE}$ (by elution) to be $28.6 \%$ and $\mathrm{Hb} \mathrm{F}$ ( by Singer's method) as $0.6 \%$. The electrophoresis pattern showed a major band at AF region and a less prominent band at $\mathrm{E}$ region giving the impression of heterozygous $\mathrm{HbE}$ trait. The father showed a normal $\mathrm{Hb}$ electrophoresis pattern. An earlier HPLC report of our patient at one and half year of age showed $\mathrm{Hb} F$ to be $2 \%, \mathrm{Hb} \mathrm{A}_{2}+\mathrm{E}$ to be $28 \%$, the impression being given of $\mathrm{HbE}$ trait.

As we could not explain why $\mathrm{HbE}$ trait would cause so much anemia or splenohepatomegaly when she presented to us for the first time at two and half years of age, we carried out a thorough laboratory work-up.

A blood count revealed $\mathrm{Hb}$ level of $6.9 \mathrm{gm} / \mathrm{dl}$, and a reduced platelet count of $7000 / \mathrm{cu} \mathrm{mm}$. The peripheral smear showed normocytic and microcytic hypochromic RBCs with moderate thrombocytopenia. Nucleated RBCs were absent.

Bone marrow aspirate (Fig. 1) revealed storage cells with basophilic fibrillar cytoplasm, eccentric nucleus resembling Gaucher's cells present in good numbers. There was normal maturation of megakaryocytic, granulocytic and erythroid cells.

Bone marrow trephine biopsy (Fig. 2) revealed sheets of large cells replacing hematopoietic marrow over many areas. These cells showed single or multiple small irregular nuclei with fine nuclear chromatin and abundant cytoplasm. Many of the cells showed wrinkled paper appearance of the cytoplasm. Islands of 
hematopoietic marrow with sequential maturation were also present. Reticulin stain showed intersecting fine reticular fibers over focal areas. All these findings were suggestive of Gaucher's disease.

Serum ferritin was marginally increased. Tests for HBsAg and anti-HCV antibody were non-reactive. Serial blood counts showed $\mathrm{Hb}$ in the range of 7-9 gm/dl, a rapidly declining platelet count with a minimum recorded count of $52000 / \mathrm{mm}^{3}$ and a falling trend in leukocyte count $\left(\right.$ minimum $\left.=3800 / \mathrm{mm}^{3}\right)$. Hypochromic, microcytic anemia with normal Red cell distribution width (RDW) were consistently found.

Prothombin time and Activated Partial Thromboplastin time were within normal limits.Liver biopsy showed focal collections of macrophages having abundant, pale, acidophilic cytoplasm with some showing striations. These cells showed diastase resistant PAS positive material. All these findings were strongly suggestive of Gaucher's disease.Finally, Enzyme analysis confirmed the diagnosis of Gaucher's disease. Beta glucosidase in leukocytes was markedly reduced and in plasma chitotriosidase was significantly increased, thereby establishing the diagnosis of Gaucher's disease Type I.

\section{Discussion}

$\mathrm{Hb} \mathrm{E}$ trait, the second most common globin mutation worldwide, is asymptomatic in heterozygotes and causes mild microcytic anemia in homozygotes ${ }^{1}$. Our case, about $2 \frac{1}{2}$ years old on first presentation had four units of packed RBCs since her first transfusion at eight months of age. The child maintained a Hb level of 7-11 $\mathrm{gm} / \mathrm{dl}$ in between transfusions. Though the frequency of transfusions had not been high, the need for blood transfusion in haemoglobin E trait was rather unusual. The child had a normal facies and a firm splenomegaly and hepatomegaly with increments in splenic size of $4 \mathrm{~cm}$ and in liver size of $2 \mathrm{~cm}$ in the two and half year of her follow up with us. As of now, the spleen is palpable $14 \mathrm{~cm}$ in its long axis and the liver is palpable $7 \mathrm{~cm}$ in the midclavicular line and $8 \mathrm{~cm}$ at the epigastrium. A rapid decline in the platelet count and gradual decline in leukocyte count could be explained by the hypersplenism resulting from massive splenomegaly and also the bone marrow infiltration by Gaucher's cells. The moderate degree of microcytic hypochromic anemia necessitating intermittent blood transfusions can be explained by the chronicity of the disease state and with further aggravation by nutritional imbalances. The normal reticulocyte count and RDW have negated the possibility of any haemolytic factor in the causation of anemia.. The absence of evidence of any hemophagocytosis by Gaucher's cells in the histopathology of the bone marrow biopsy specimen and only a slighty raised serum ferritin further ruled out hemolysis as a major cause of anemia.

Gaucher-like or PseudoGaucher cells have been reported by a few authors in association with classical beta thalassemia major, $\mathrm{Hb} \mathrm{E}$ disease (EE), thalassemia intermedia, chronic myeloid leukemia,multiple myeloma, etc. However, either enzyme study for beta glucosidase in leukocytes or skin fibroblasts or a search for birefringent crystals in Gaucher like cells have ruled out Gaucher disease. All these conditions are characterized by enhanced cell turnover with accumulation of beta-glucosidase enzyme in the lysosomes of the mononuclear phagocyte cells by the cell membrane derived glycosylceramide ${ }^{[2]}$. These represent a relative rather than absolute deficiency of the enzymes in the histiocytes ${ }^{[4],[5]}$. Interestingly in one report of monoclonal gammopathy of undetermined significance, these cells had the morphological and immunological features of plasma cells rather than macrophages ${ }^{[6]}$. However other authors concluded on immunoelectrophoresis and electron microscopy, that the Pseudo-Gaucher cells even in a case of myeloma were marrow macrophages engorged with immunoglobulin ${ }^{[7]}$. While most described these cells in the bone marrow, a few reports document them at other locations like peritoneal fluid ${ }^{[8]}$, spleen ${ }^{[9],[10]}$ and lymphnode ${ }^{[11],[12]}$.

In our patient the presence of sheets of Gaucher cells in the bone marrow biopsy specimen, focal collection of PAS positive \& diastase resistant Gaucher cells in liver biopsy specimen, a reduced beta glucosidase activity in leukocytes and a significant increase in plasma chitotriosidase ${ }^{[13]}$ clinched the diagnosis of Gaucher disease Type I in association with $\mathrm{HbE}$ trait.

\section{CONCLUSION}

This report stresses the need to always look for the presence of storage disorders like Gaucher's Disease in any clinical case presenting as thalassemia -like syndrome where the hemoglobin electrophoresis report does not match with the severity of symptoms. Though the presence of Gaucher like cells has been reported by a few other authors in association with thalassemia -like syndromes, Gaucher's disease was never documented in their reports.Our case, we believe, is probably the first such report. There is also a need to evaluate whether the co-existence of a thalassemia-like syndrome with a storage disorder might influence the clinical course of each other. 


\section{REFERENCES.}

[1] Katsanis E, Luke KH, Hsu E, Yates JR.Hemoglobin E: a common hemoglobinopathy among children of Southeast Asian origin. Can Med Assoc J. 1987;137:39-42.

[2] Zaino EC, Rossi MB, Pham TD, Azar HA. Gaucher's cells in thalassemia. Blood 38:457-462, 1971.

[3] Sharma P, Khurana N, Singh T :Pseudo-Gaucher cells in Hb E disease and thalassemia intermedia.Hematology. 2007 Oct; 12(5): 457-9

[4] Stewart AJ, Jones RD. Pseudo-Gaucher cells in myelodysplasia. J Clin Pathol 1999;52:917-918.

[5] Carrington PA, Stevens RF, Lendon M. Pseudo-Gaucher cells. J Clin Pathol 1992;45(4):360.

[6] Regazzoli A, Pozzi A, Rossi G. Pseudo-Gaucher plasma cells in the bone marrow of a patient with monoclonal gammopathy ofundetermined significance. Haematologica 1997;82:727.

[7] Scullin DC, Jr, Shelburne JD, Cohen HJ. Pseudo-Gaucher cells in multiple myeloma. Am J Med 1979;67(2):347-352.

[8] Lang E, Uthman M. Pseudo-Gaucher cells in peritoneal fluid: An uncommon manifestation of extramedullary hematopoiesis.Diagn Cytopathol 1999;20(6):379-381.

[9] Robak T, Urbanska-Rys H, Jerzmanowski P, Bartkowiak J, Liberski P, Kordek R. Lymphoplasmacytic lymphoma withmonoclonal gammopathy-related pseudo-Gaucher cell infiltration in bone marrow and spleen-diagnostic and therapeutic dilemmas. Leuk Lymphoma 2002;43(12):2343-2350.

[10] Ishihara T, Yamashita Y, Okuzono Y, Yokota T, Takahashi M, Kamei T, Uchino F, Matsumoto N, Miwa S, Fuji H, et al. Three kinds of foamy cells in the spleen: Comparative histochemical and ultrastructural studies. Ultrastruct Pathol 1985;8(1):13-23.

[11] Links TP, Karrenbeld A, Steensma JT,Weits J, van der Jagt EJ Postmus PE. Fatal respiratory failure caused by pulmonary infiltration by pseudo-Gaucher cells. Chest 1992; 101(1):265-266

[12] Dunn P, Kuo MC, Sun CF. Pseudo-Gaucher cells in mycobacterial infection: A report of two cases. J Clin Pathol 2005;58(10):1113-1114

[13] Barone R, Sotgiu S, Musumeci S. Plasma chitotriosidase in health and pathology. Clin Lab. 2007;53(5-6):321-33.

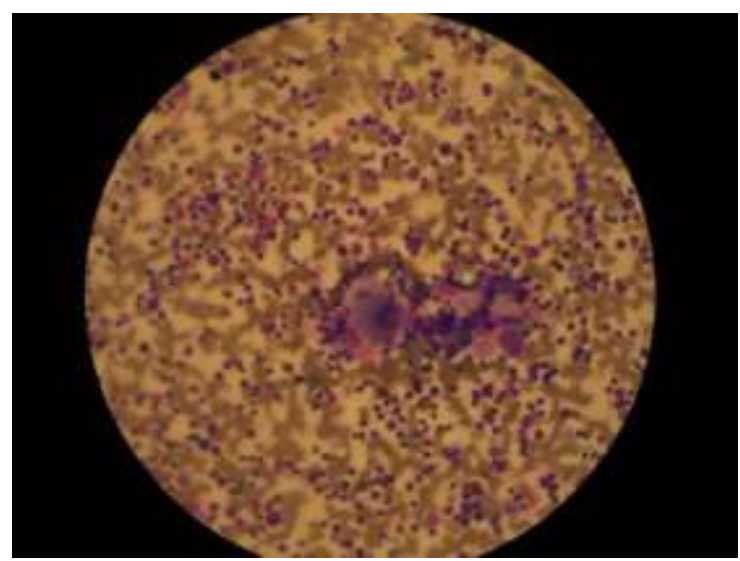

Fig. 1 : Bone marrow aspirate revealed storage cells with basophilic fibrillar cytoplasm, eccentric nucleus resembling Gaucher's cells (High Power)

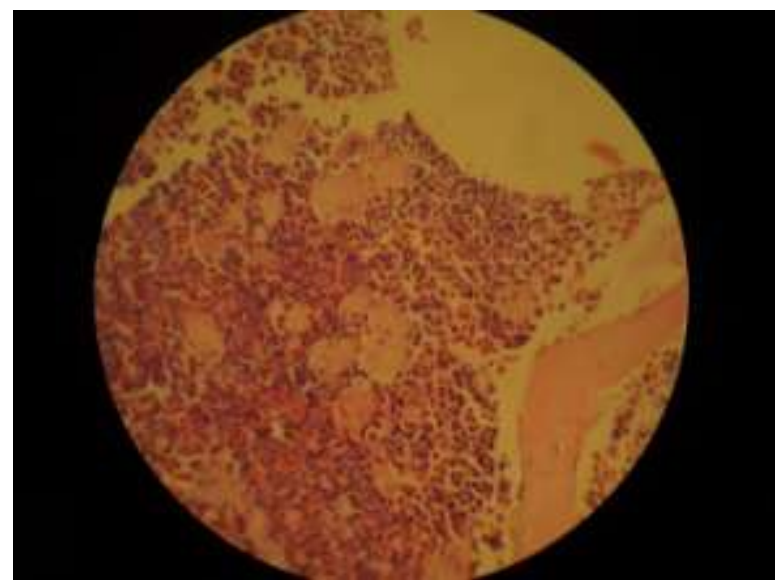

Fig. 2: Bone marrow trephine biopsy revealed sheets of large cells replacing hematopoietic marrow over many areas (High Power) 